D. Patalakh, orcid.org/0000-0001-8264-8625, A. Prykhodko, orcid.org/0000-0001-6258-6826, K. Lut, orcid.org/0000-0002-9842-3540, S. Tykhovod, orcid.org/0000-0003-0748-1735
Zaporizhzhia Polytechnic National University, Zaporizhzhia, Ukraine, e-mail: stikhovod@gmail.com

\title{
IMPROVEMENT OF MODELING TECHNIQUES OF TRANSIENTS IN TRANSFORMERS BASED ON MAGNETOELECTRIC EQUIVALENT SCHEMES
}

Purpose. Use of an improved numerical method of calculating transient processes in electrical circuits for modeling electromagnetic processes in nonlinear magneto-electric circuits, and also development of a circuit model based on this method, which leads to the convenience of calculation.

Methodology. Approximation of functions by Chebyshev's polynomials, numerical methods of differential equations integrating, matrix methods, spline interpolation, programming, theory of electric and magnetic circuits.

Findings. On the base of the well-known method of transient process analysis in linear electric circuits, the method of numerical calculation of transient processes in nonlinear magneto-electric equivalent circuits of transformer has been developed. By the help of the proposed method it is possible to reduce processing time for modeling electromagnetic processes in transformers. The example of using the developed method is shown. The computer program for modeling of electromagnetic transient in a single-phase transformer based on the described method has been developed. This example shows reduction of processor time by more than four times compared to examples of calculations based on other known methods.

Originality. The method in which the solution of state differential equations is presented in the form of decomposition into a series along orthogonal Chebyshev's polynomials is used in this work. The polynomial approximation applied in this work is not corresponding to the solution function itself, but its derivative, which significantly reduces the error of integration of differential equations. Differential equations of state are transformed into linear algebraic equations for special images of solution functions. A principle is developed of constructing magneto-electric substitution circuits in which images of solution functions appear. Images of true dynamic currents and magnetic fluxes in the proposed equivalent scheme are interpreted as direct currents and direct magnetic fluxes. The used method has shown advantages in accuracy and time of simulation of electromagnetic transient over other known methods based on application of magneto-electric substitution circuits.

Practical value. The developed method opens up the possibility of using the apparatus of the theory of electric and magnetic circuits to work with images of currents and magnetic fluxes. Based on this, a universal software complex is being developed to calculate transients in transformers of various constructions.

Keywords: transient electromagnetic process, differential equations, circuit model, polynomial approximation, Chebyshev's polynomials, transformer

Introduction. Modeling of dynamic processes in electrical circuits is performed by many researchers using existing software systems, such as EMTP [1], PSpice [2], Simulink [3] and others. These software systems are based on equations of state that are automatically generated by the program according to Kirchhoff's laws for instantaneous values of variables.

For the analysis of transient electromagnetic processes in electric and magnetic circuits, hybrid circuits are successfully used by combining the magnetic and electric circuits into a single scheme. The combined magnetic and electric circuits make up the so-called "magneto-electric" circuit. Magnetoelectric circuits are characterized by the presence of controlled sources that mutually control each other. In this case, so-called "algebraic loops" are formed, which are not allowed in the calculation when using EMTP, PSpice, Simulink, and others.

The studied electrical circuits of real devices usually contain hundreds of different elements, which leads to the large systems of state equations in the analysis. Transients in transformers can be very long, and the simulation time of such processes can be significant, which is undesirable. Modern requirements of design engineers are such that the speed of calculations must be increased so that simulation in real time has to be possible. Therefore, an urgent task is to develop an improved method for calculation of electromagnetic processes transient, which are faster than existing methods, stable and no sensitive to "algebraic loops".

Literature review. For the analysis of transients in electrical circuits, numerical methods of integrating of ordinary differ-

(C) Patalakh D., Prykhodko A., Lut K., Tykhovod S., 2021 ential equations usually are used [4]. The same methods were used to analyze transient processes in electrical circuits [5] and magneto-electric equivalent circuits of electromagnetic devices [6]. In the work [7], the interaction of electric and magnetic circuits was carried out using gyrators or mutators [8], which transform the function of magnetic flux into a derivative of magnetic flux over time using capacitive elements.

The problem of increasing the rate of simulation of transients in magneto-electric substitution schemes led to the search of new methods for numerical integration of differential equations of state.

Work [9] describes the principle of using Chebyshev's polynomials to solve ordinary differential equations. In work [10] computational features of minimization of error of approximations of functions on Chebyshev's interpolation nodes are studied. The paper [11] shows the perspective of using Chebyshev's polynomials for analysis of transient processes in transformers, and also in asynchronous motors based on magneto-electric equivalent circuits. The works of many mathematicians is devoted to the properties of Chebyshev's polynomials. Recently, interest in Chebyshev's polynomials has not faded, as it is evidenced by work [12] or work [13]. In work [14], an approximation of the solution for the current function in the electric circuit by series of Chebyshev's polynomials is used. As a result, the method is obtained that allows you to significantly increase the simulation speed. When function is approximated with the help of series of Chebyshev's polynomials, the condition of the collocation method is given. This means that for the selected $N$ node points with the value of argument-time $t_{m}$, the approximated solution matches the ex- 
act solution, but some error is assumed at other points. The error analysis of the method was carried out in work [14], where it is demonstrated that the main error of the method arises in the calculation process of the solution derivative.

To get rid of the procedure for calculating the derivative of the solution based on the approximation of the solution by polynomials in [12], it is proposed to apply Chebyshev's polynomials not to the solution function itself, but to the derivative of the solution. Chebyshev's polynomials have an important property of uniformity of the approximation error over the whole range of argument variation. The solution function itself can be found by applying the integration operation, which has a small error.

Purpose. The aim of this work is to modify a well-known numerical method for analyzing transients in electrical circuits for simulating transient of electromagnetic processes in transformers based on magneto-electric equivalent schemes. A special feature is the use of approximation of derivatives of the solution by Chebyshev's polynomials, and also using of special value "magnetic current" - derivative of magnetic flux function of time. It significantly reduces the simulation time on computer.

Results. We present a method for calculating transients in transformers in this paper, using the method described in [15]. The basics of this method are as follows.

Let us consider a simple electrical circuit that contains elements included in series: resistive $(R)$, inductive $(L)$. When the $E M F$ source $e(t)$ is switched on at the time $t=0$, a transient process $i(t)$ occurs in this circuit, which is described by a linear differential equation with constant coefficients

$$
L \frac{d i(t)}{d t}+R i(t)=e(t) .
$$

The solution is defined in the time domain $t \in[a, b]$. We use a method that eliminates the appearance of errors associated with the calculation of production. To do this, we lay out the series of Chebyshev's polynomials not the solution function itself, but its derivative. Chebyshev's polynomials are determined on the segment of the argument $x \in[-1,1]$. When moving to the time domain $t \in[a, b]$, the values of the argument are recalculated.

As in [15], the function for the current derivative in equation (1) is approximated by series $p(x)$ of Chebyshev's polynomials of the degree $N-1$.

$$
\frac{d i(x)}{d t}=i^{\prime}(x) \approx p(x)=c_{0} T_{0}(x)+c_{1} T_{1}(x)+\cdots+c_{N-1} T_{N-1}(x) .
$$

Let us select a series of $N$ nodal points in the simulation interval. All $N$ nodal points with the value of the argument $t_{m}\left(x_{m}\right)$ for $m=0,1,2, \ldots, N-1$, correspond to the values of the function (2): $i^{\prime}\left(x_{m}\right)=p\left(x_{m}\right)$. As a result, we get a system of $N-1$ equations. Matrix form of this system has the following view

$$
\begin{aligned}
& \mathbf{D C}=\mathbf{I}^{\prime}-\mathbf{I}_{0}^{\prime} ; \\
& \mathbf{I}^{\prime}=\left[\begin{array}{llll}
i^{\prime}\left(x_{1}\right) & i^{\prime}\left(x_{1}\right) & \ldots & i^{\prime}\left(x_{N-1}\right)
\end{array}\right]^{T} ; \\
& \mathbf{I}_{0}^{\prime}=\mathbf{I}^{\prime} \text { for } x=0 \text {. }
\end{aligned}
$$

$\mathrm{C}$ is the vector of coefficients in equation (2)

$$
\mathbf{C}=\left[\begin{array}{c}
c_{1} \\
c_{2} \\
\vdots \\
c_{N-1}
\end{array}\right] ; \quad \mathbf{D}=\left[\begin{array}{c}
\mathbf{T}\left(x_{1}\right) \\
\mathbf{T}\left(x_{2}\right) \\
\vdots \\
\mathbf{T}\left(x_{N-1}\right)
\end{array}\right]-\left[\begin{array}{c}
\mathbf{T}\left(x_{0}\right) \\
\mathbf{T}\left(x_{0}\right) \\
\vdots \\
\mathbf{T}\left(x_{0}\right)
\end{array}\right],
$$

where $T(x)=\left[\begin{array}{llll}T_{1}(x) & T_{2}(x) & \ldots & T_{N-1}(x)\end{array}\right]$ is a vector-string of Chebyshev's polynomials as a function of $x$.

The vector of derivative values for nodal points follows from equation ( 3 )

$$
\mathbf{I}^{\prime}=\mathbf{D C}+\mathbf{I}_{0}^{\prime} .
$$

The solution for the current function has the form

$$
\begin{gathered}
i(x)=\int p(x) d x+d_{1}= \\
=\int\left(c_{0} T_{0}(x)+c_{1} T_{1}(x)+c_{2} T_{2}(x)+\cdots c_{N-1} T_{N-1}(x)\right) d x+d_{1} .
\end{gathered}
$$

The integrals of expression (5) are taken from [15] and the following is obtained

$\left.i(x)=\left(\mathbf{S}_{x}(x)-\mathbf{S}_{x}\left(x_{0}\right)-\left(x-x_{0}\right) \cdot \mathbf{T}_{x 0}\right)\right) \cdot \mathbf{C}+\left(x-x_{0}\right) \cdot i_{0}^{\prime}+i_{0}$,

where $\mathbf{S}_{x}(x)$ is a vector-string as a function of the argument $x$

$$
\begin{gathered}
\mathbf{S}_{x}(x)= \\
=\left[\frac{1}{4}\left[T_{2}(x)\right], \cdots \frac{T_{k+1}(x)}{2(k+1)}-\frac{T_{k-1}(x)}{2(k-1)}, \cdots \frac{T_{N}(x)}{2 N}-\frac{T_{N-2}(x)}{2(N-2)}\right] .
\end{gathered}
$$

For $N-1$ nodal points with the value of the time argument $t_{m}$, which corresponds to the moments of the given argument $x_{m}$, which defines the values of function (7) as rows of the matrix $\mathbf{S}$.

For value $x=x_{0}$ we have $S=S_{0}$.

For $N-1$ nodal points, equation (6) is a system of equations that can be represented in matrix form

$$
\mathbf{I}=\mathbf{V} \cdot \mathbf{C}+\Delta \cdot i_{0}^{\prime}+i_{0},
$$

where

$$
\begin{gathered}
\mathbf{V}=\left(\mathbf{S}-\mathbf{S}_{0}-\Delta \cdot \mathbf{T}_{0}\right) ; \\
\Delta=\left[\begin{array}{l}
x-x_{1} \\
x-x_{2} \\
\vdots \\
x-x_{N-1}
\end{array}\right] .
\end{gathered}
$$

The differential equation of state for the circuit $R-L-e$ has the form (1). For nodal points with the value of the time argument $t_{m}$ (according to $x_{m}$ ) $m=1,2, \ldots, N-1$ corresponds to the following equation in matrix form

$$
L \mathbf{I}^{\prime}+R \mathbf{I}=\mathbf{e},
$$

where $\mathbf{e}$ is a vector of EMF values at nodal points; $\mathbf{I}$ is a vector of current values at the nodal points; $\mathbf{I}^{\prime}$ is a vector of current derivative values at nodal points.

Let us substitute the expressions $I^{\prime}$ (4), I (8) in equation (11) and get

$$
(L \cdot \mathbf{D}+R \cdot \mathbf{V}) \cdot \mathbf{C}=\mathbf{e}-R \cdot \Delta \cdot \mathbf{I}_{0}^{\prime}-R \cdot i_{0}-L \cdot \mathbf{I}_{0}^{\prime} .
$$

This is an expression of the second Kirchhoff law for images $\mathbf{C}$. Solution of equation (12) gives the vector $\mathbf{C}$. Then, for known initial values of the current $i_{0}$ and the derivative of the current $i_{0}^{\prime}$, it is possible to determine the current values at all arbitrary points $x$ on the segment $[-1,1]$ or at nodal points according to (8).

Equation (12) in the work [15] is interpreted as follows: "Let the real current $i(t)$ flow in the original branch $R-L-e$. The replacement branch corresponds to the original branch (Fig. 1), via the which a certain image $\mathbf{C}$ of the real current $i(t)$ is flowing. The image $\mathbf{C}$ is a vector containing the coefficients of expansion of the current $i(t)$ in a series of orthogonal Chebyshev's polynomials. Resistive element $R$ in the substitution branch has a resistance $R \cdot \mathbf{V}$ and a source of direct EMF having value $-R \cdot\left(\Delta \cdot \mathbf{I}_{0}^{\prime}+\mathbf{I}_{0}\right)$ is subsequently connected with it [15, Fig. 1]. The inductive element $L$ in substitution branch has a resistance $L \cdot \mathbf{D}$, and a direct EMF source having value $-L \cdot \mathbf{I}_{0}^{\prime}$ connected in series with it".

In [15], it is proved that "the first Kirchhoff law is also observed in the nodes of the substitution scheme for images C".

Thus, all images $C_{k}$ of the original currents $i_{k}(t)$ in equivalent scheme of electrical circuit satisfy to the Kirchhoff laws. The state equations for the equivalent scheme for images are linear algebraic equations. Therefore, for known values of branches' currents and their derivatives at the beginning of the modeled time segment $\left[t_{0}, t_{N-1}\right]$, the system of equations for all 
nodes without one and for all main circuits compiled for the equivalent scheme according to the first Kirchhoff law has a unique solution. As a result of solving a system of linear algebraic equations, we obtain vectors $C_{k}$ (here $k$ is the number of the branch) containing the values of the coefficients of the polynomial approximation of currents for all branches.

The order of numerical calculation of the transients in magneto-electric equivalent schemes based on the use of Chebyshev's polynomials. In this paper, we will use magneto-electric equivalent schemes (MEES) for numerical calculation of electromagnetic transients in transformers. A special feature of the MEES is the use of the concept of "magnetic current" (the derivative of the magnetic flux function of time). To solve the equations of state, we will use the approximation of the derivatives of the solution by expansion in a series of Chebyshev's polynomials. This method provides a number of significant advantages when processes in equivalent magneto-electric schemes of transformer are analyzed.

Before considering the modeling of electromagnetic processes in a transformer, we will describe the well-known principle of MEES composition. Unification of the magnetic and electric circuits into one, magneto-electric circuit, allows carrying out simultaneous research on interconnected magnetic and electrical processes. In the work [6], so-called magnetic capacitors are used, and in the work [7], gyrators are used. Voltage sources controlled by the help of current or magnetic flux are usually applied in magneto-electric circuits. By the means of them interaction between processes in the electric and magnetic circuits is realized.

The principle of compiling MEES is shown by the example of a coil containing $N_{w}$ turns. The coil is located on a closed ferromagnetic core with a length of the middle line 1 . We believe that the magnetic permeability of the magnetic core is large and the whole magnetic field is concentrated in it.

If you connect an alternating voltage source $e(t)$ to the coil, an electric current $i(t)$ will flow through the coils, and a magnetic flux $\Phi$ is created in the magnetic circuit. According to the law of total current

$$
H \cdot \ell=N_{w} \cdot i,
$$

where $H$ is the magnetic field intensity.

Let us convert the expression (13) using the designation of differential magnetic permeability

$$
\begin{gathered}
\mu^{d}=\frac{d B}{d H} ; \\
\frac{\ell}{S \mu^{d}} \frac{d \Phi}{d t}=N_{w} \frac{d i}{d t},
\end{gathered}
$$

where $S$ is the cross-sectional area of the magnetic core; $B$ is magnetic induction.

Equation (14) is presented in a new form

$$
R^{d} \frac{d \Phi}{d t}=N_{w} i^{\mu},
$$

where $i^{\mu}$ is magnetic current; $R^{d}$ is the differential magnetic resistance of the magnetic core

$$
R^{d}=\frac{\ell}{\mu^{d} S} .
$$

Equation (15) could be interpreted as follows. A "magnetic current" flows through the magnetic core, whose value is equal to the time-dependent derivative of magnetic flux $\Phi$. In the works by M. Shakirov, it is proposed to use the concept of magnetic displacement current $i^{\mu}=d \Phi / d t$ by analogy with the electric displacement current with density $d D / d t$. The term "magnetic current" was proposed by O. Heaviside at first. Further, the concept of magnetic current was used in the works by other authors for the analysis of electromagnetic processes based on MEES.
A coil mounted on a ferromagnetic core could be represented as a MEES (Fig. 1). Electrical part of the MEES contains an EMF source $e(t)$, some resistance $R$, and a voltage source controlled by a derivative of the magnetic flux $\Phi_{2}^{\prime}$ with a coefficient $N_{w}$.

The magnetic circuit contains a resistive element $R^{d}$ and a voltage source controlled by a current derivative $i_{1}$, with a coefficient $N_{w}$. The element $R^{d}$ has a value of differential magnetic resistance. A "magnetic current" $\Phi$ ' passes through the magnetic circuit.

Based on the method given in [15], the scheme in Fig. 1 is replaced by the scheme in Fig. 2 for images of current and magnetic flux.

A transient of electromagnetic process which occurs when a single-phase transformer is closed to a sinusoidal voltage source is studied in [6]. In this paper we used the magnetoelectric equivalent circuit of the transformer. The calculation was carried out using the well-known Geer numerical method. The calculation of derivative currents was carried out by the help of special differential circuits. Let us consider the same example, but we will analyze it using the method described in [15]. The design view in the section of a two-winding transformer is shown in Fig. 2 of the work [6]. In this figure magnetic flows flowing in elements of magnetic core $(\Phi 3, \Phi 6)$ and in gaps $(\Phi 4, \Phi 5)$ are considered. Magnetic resistances of gaps (dispersion channels) $R_{m 4}, R_{m 5}$ are constant.

On the basis of the principles of construction of magnetoelectric substitution circuits for coils with ferromagnetic cores, the single-phase transformer is replaced by a substitution circuit, which has the view shown in Fig. 3. The substitution scheme takes into account the symmetry of the transformer design. A special feature of this scheme is that "magnetic currents" pass in the branches of the magnetic part of the circuit. In such a hybrid circuit the electric and magnet branches are presented. Electric currents flow through the electric branches, and "magnetic currents" pass through the magnetic branches - time-derivative of magnetic fluxes. The use of magnetic currents made it possible to stop using gyrators [9] or mutators [10], which, using capacitive elements, transformed the function of magnetic flux into a derivative of magnetic flux over time. The scheme is simplified due to exclusion of capacitive differentiating circuits used in the work [6].

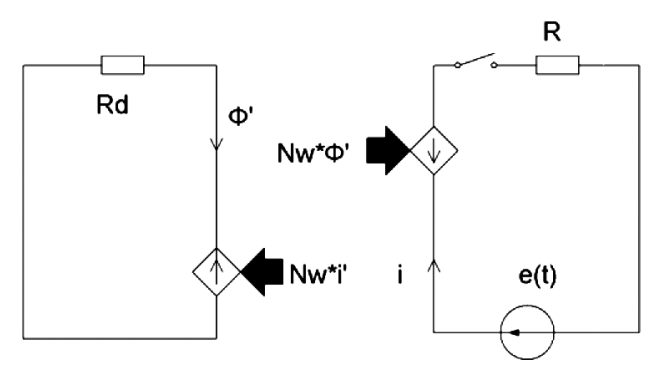

Fig. 1. Magneto-electric scheme of interaction of current and magnetic flux into the coil located on a ferromagnetic core

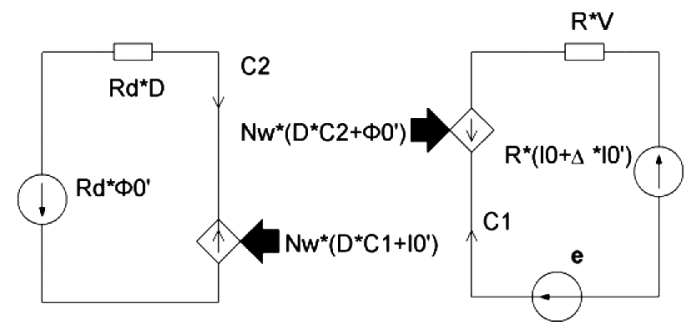

Fig. 2. Magneto-electric scheme of interaction images of current and magnetic flux into the coil located on a ferromagnetic core 

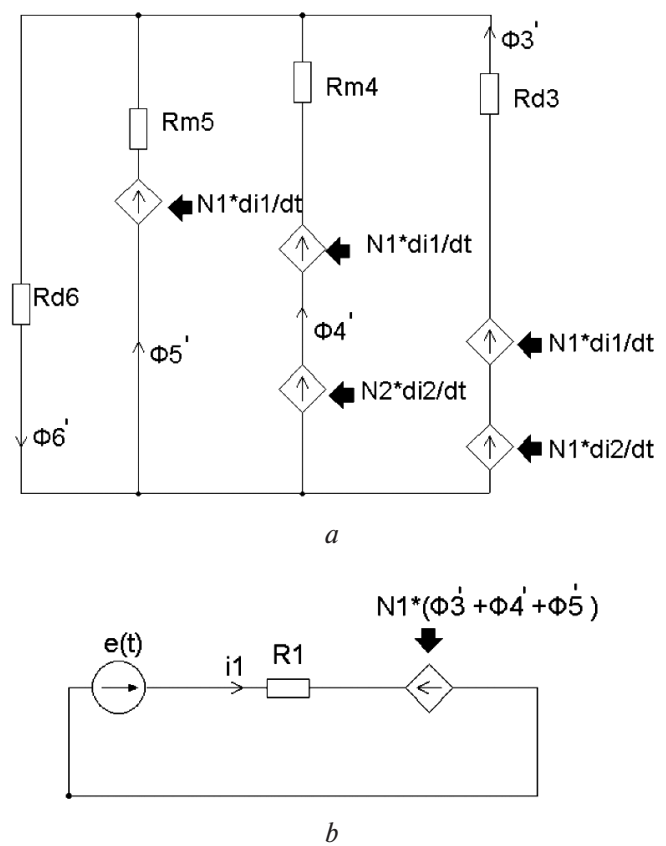

Fig. 3. MEES of a single-phase transformer:

$a$ - magnetic circuit; $b$ - primary winding, with a voltage source; $c$ - secondary winding with load resistance

Magnetic fluxes in the magnetic branch cause magnetic voltage drops which are equal to product of magnetic-field intensity $\mathrm{H}$ and the length of magnetic branch $l$.

The system of equations compiled according to the Kirchhoff laws for the circuit shown in Fig. 3 will take the form

$$
\left.\begin{array}{l}
-\Phi_{6}^{\prime}+\Phi_{5}^{\prime}+\Phi_{4}^{\prime}+\Phi_{3}^{\prime}=0 \\
-R_{d 6} \Phi_{6}^{\prime}-R_{m 5} \Phi_{5}^{\prime}+N_{1} i_{1}^{\prime}=0 \\
R_{m 5} \Phi_{5}^{\prime}-R_{m 4} \Phi_{4}^{\prime}+N_{2} \frac{d i_{2}}{d t}=0 \\
R_{m 4} \Phi_{4}^{\prime}-R_{d 3} \Phi_{3}^{\prime}=0 \\
R_{1} i_{1}+N_{1} \Phi_{3}^{\prime}+N_{1} \Phi_{4}^{\prime}+N_{1} \Phi_{5}^{\prime}=e(t) \\
R_{2} i_{2}+N_{2} \Phi_{3}^{\prime}+N_{2} \Phi_{4}^{\prime}=0
\end{array}\right\}
$$

Fig. 4 shows the MEES of the single-phase transformer for images of electrical and magnetic currents according to the principles stated in work [15].

For the scheme in Fig. 4, the system of equations composed for images of electric and magnetic currents will take the form

$$
\begin{aligned}
& \mathbf{C}_{6}-\mathbf{C}_{5}-\mathbf{C}_{4}-\mathbf{C}_{3}=\mathbf{0} \\
& -K_{n} \mathbf{R}_{d 6} \mathbf{C}_{6} \mathbf{D}-K_{n} \mathbf{R}_{m 5} \mathbf{C}_{5} \mathbf{D}+N_{1} K_{n} \mathbf{C}_{1} \mathbf{D}=K_{n} \mathbf{R}_{d 6} \Phi_{06}^{\prime}+ \\
& \quad+K_{n} R_{m 5} \Phi_{05}^{\prime}-N_{1} K_{n} i_{01}^{\prime} \\
& K_{n} R_{m 5}\left(\mathbf{C}_{5} \mathbf{D}+\Phi_{05}^{\prime}\right)-K_{n} R_{m 4}\left(\mathbf{C}_{4} \mathbf{D}+\Phi_{04}^{\prime}\right)+ \\
& \quad+N_{2} K_{n}\left(\mathbf{C}_{2} \mathbf{D}+i_{02}^{\prime}\right)=0 \\
& K_{n} R_{m 4}\left(\mathbf{C}_{4} \mathbf{D}+\Phi_{04}^{\prime}\right)-K_{n} \mathbf{R}_{d 3}\left(\mathbf{C}_{3} \mathbf{D}+\Phi_{03}^{\prime}\right)=0 \\
& R_{1}\left(\mathbf{C}_{1} \mathbf{V}+i_{01}+\Delta \cdot i_{01}^{\prime}\right)+K_{n} N_{1}\left(\mathbf{C}_{3} \mathbf{D}+\Phi_{03}^{\prime}+\mathbf{C}_{4} \mathbf{D}+\right. \\
& \left.\quad+\Phi_{04}^{\prime}+\mathbf{C}_{5} \mathbf{D}+\Phi_{05}^{\prime}\right)=\mathbf{e} \\
& R_{2}\left(\mathbf{C}_{2} \mathbf{V}+i_{02}+\Delta \cdot i_{02}^{\prime}\right)+K_{n} N_{2}\left(\mathbf{C}_{3} \mathbf{D}+\Phi_{03}^{\prime}+\mathbf{C}_{4} \mathbf{D}+\right. \\
& \left.\quad+\Phi_{04}^{\prime}\right)=0
\end{aligned}
$$

where $K_{n}$ is the normalization coefficient associated with replacing the argument $t$ by $x$.

In matrix form, the system (18) has the form

$$
\mathbf{Z} \cdot \mathbf{C}=\mathbf{F},
$$

where according to (18)
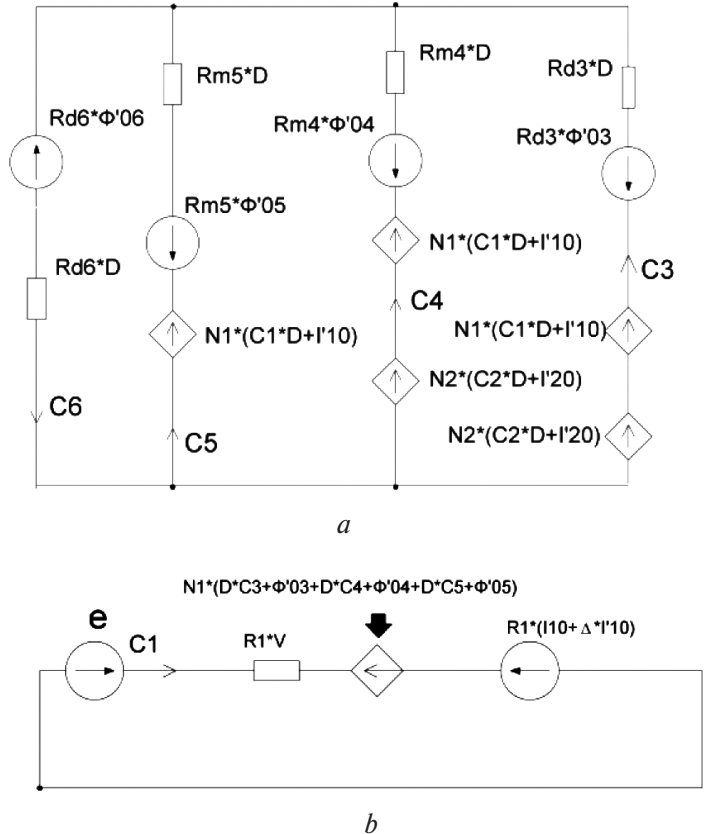

Fig. 4. MEES of a single-phase transformer for images of currents and magnetic fluxes:

$a$ - magnetic circuit; $b$ - primary winding with EMF source; $c$ secondary winding with load resistance

$$
\mathbf{Z}=\left[\begin{array}{c:c:c:c:c:c}
0 & 0 & -1 & -1 & -1 & 1 \\
\hdashline N_{1} \cdot \mathbf{D} & 0 & 0 & 0 & -\mathbf{R}_{m 5} \mathbf{D} & -\mathbf{R}_{d 6} \mathbf{D} \\
\hdashline 0 & N_{2} \cdot \mathbf{D} & 0 & -R_{m 4} \mathbf{D} & R_{m 5} \mathbf{D} & 0 \\
\hdashline 0 & 0 & -\mathbf{R}_{d 3} \mathbf{D} & R_{m 4} \mathbf{D} & 0 & 0 \\
\hdashline R_{1} \mathbf{V} & 0 & K_{n} N_{1} \mathbf{D} & K_{n} N_{1} \mathbf{D} & K_{n} N_{1} \mathbf{D} & 0 \\
\hdashline \mathbf{0} & R_{2} \mathbf{V} & K_{n} N_{2} \mathbf{D} & K_{n} N_{2} \mathbf{D} & 0 & 0
\end{array}\right] ;
$$

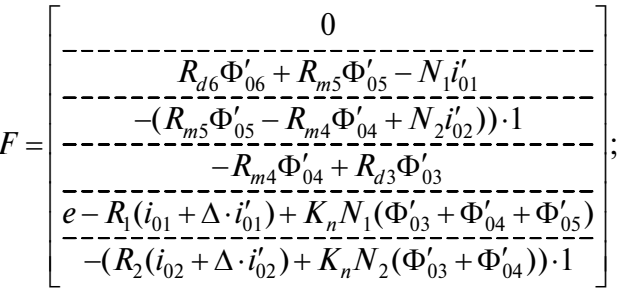

$$
\begin{aligned}
& \mathbf{C}=\left[\begin{array}{llllll}
\mathbf{C}_{1} & \mathbf{C}_{2} & \mathbf{C}_{3} & \mathbf{C}_{4} & \mathbf{C}_{5} & \mathbf{C}_{6}
\end{array}\right]^{T} .
\end{aligned}
$$

The solution of equation (19) can be found as

$$
\mathbf{C}=\mathbf{Z}^{-1} \cdot \mathbf{F} \text {. }
$$

To reduce the error on large intervals of simulation time, all the simulation time is divided into $N_{u}$ intervals and equation (22) is solved at each interval. An iterative cycle is organized at each interval for sequential recalculation of the values of magnetic resistances basing on the magnetization curve. The magnetization curve is set by arrays of values $B, H$, and the calculation uses spline interpolation, which is worked out by Carl de Boor [16]. Usually 5-7 iterations are enough for the calculation error to be practically acceptable, i.e. the maximum error does not exceed $2 \%$. If the number of iterations exceeds the specified maximum value, the current time interval $\tau$ is reduced by half. If the number of iterations becomes less than the specified minimum number during the specified number of steps, the time interval is doubled in the computer program. The maximum value of the iterations number is set by selection based on the actual simulation time and calculation error.

Calculation algorithm and the computer program Tr1 VDW $\mathrm{C}$ were created according to the developed method. The simulation results are shown in Fig. 5. 


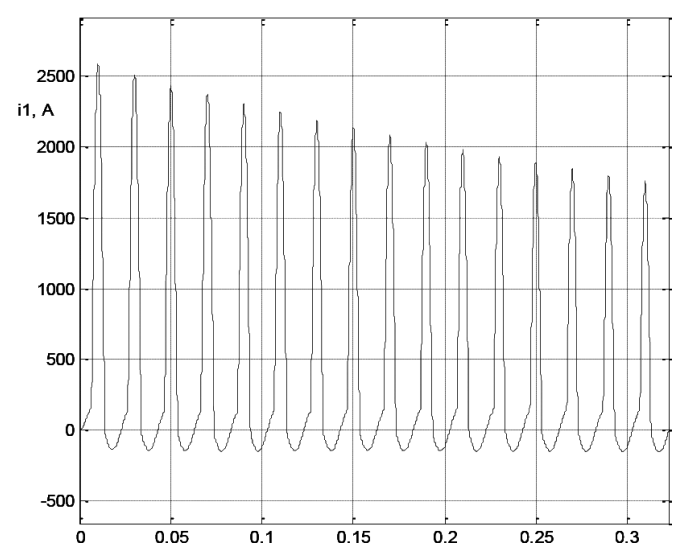

$a$

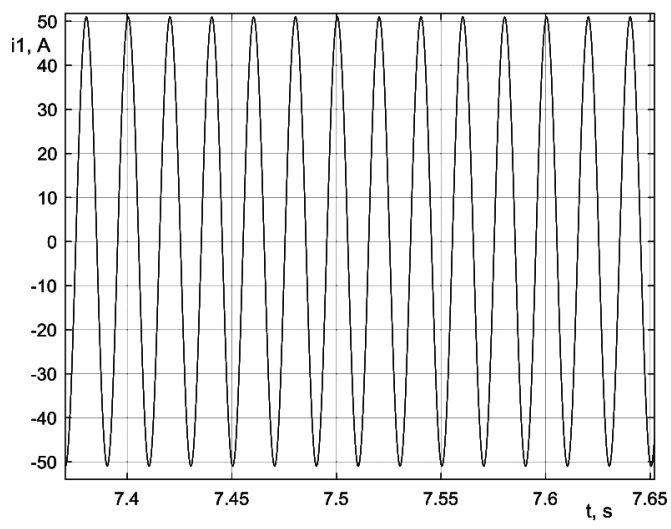

$b$

Fig. 5. Dependence of primary winding current on time:

$a$-in the initial section of the transient; $b$ - in the section of the steady-state process

It is seen from Fig. 5 that scheme in the transformer is a very long one. At the initial moment the magnetic circuit enters in saturation and the current value in the windings is in many times greater than it value in the steady state. The current waveform is much distorted. In the steady-state mode, the current waveform becomes a sinusoidal one. However, the calculation with the help of the proposed method is more quickacting if it has the same accuracy.

Conclusions. The calculation of transients in electromagnetic devices based on magneto-electric equivalent schemes reduces to solving a system of differential-algebraic equations of state. A feature of the MEES used in this work is the applying of the concept of "magnetic current" - the time derivative of the magnetic flux. The proposed method allows reducing the differential equations of state to algebraic equations. The method is based on approximation of the derivative of the solution by Chebyshev's polynomials. This representation is well suited for the approximation of the magnetic currents by MEES. It is proposed to use a special equivalent scheme of electric and magnetic currents' images for creating equations of state for images of currents. Computer program for modeling the transients in a transformer was developed to demonstrate the method and verify its adequacy. Comparison of the processor time for calculating the transient process, when the transformer is switched on, using the proposed method and the Geer method described in [6] has showed that for the same set error, the proposed method has reduced the processor time by four times.

References.

1. Eiichi, H., Tadashi, K., Junichi, A., \& Hisatochi, I. (2016). Power System Transient Analysis: Theory and Practice using Simulation Programs (ATP-EMTP). ISBN: 978-1-118-73749-1. $280 \mathrm{p}$.
2. Akulin, A., \& Suponin, A. (2017). Modeling and Advanced Circuit Analysis in PSpice. Electronics Science. Technology. Business, 82-91. https://doi.org/10.22184/1992-4178.2017.171.10.82.91.

3. Chernykh, I.V. (2014). Modeling of electrical devices in MATLAB, SimPowerSystems and Simulink. Moscow: DMK Press. St. Petersburg: Peter. Publ. SBN 5-94074-395-1 ("DMK Press"). ISBN 978-5-38800020-O ("Peter").

4. Bansal, R. K. (2018). Fundamentals of Numerical Methods. Oxford: Alpha Science International Ltd. ISBN 1783323604.

5. Smancer, D. S. (2019). Simulation of transients in electrical circuits of periodic non-sinusoidal current. Scientific and Practical Conference "Issues of Technical and Physical and Mathematical Sciences in the Light of Modern Studies”, 8-9(15), 5-11. Retrieved from: https://libeldoc.bsuir.by/bitstream/123456789/37109/1/Smantser_Modelirovaniye.pdf.

6. Tikhovod, S. M. (2014). Modification of magnetoelectric substitution circuits of electromagnetic devices for analysis of transient processes. Elektrichestvo, (2), 53-60. ISSN: 0013-5380. eISSN: 2411-1333. 7. Guadalupe, G. Gonzalez, \& Mehrdad Ehsani (2018). Power-Invariant Magnetic System Modeling. International Journal of Magnetics and Electromagnetism, 4(1). https://doi.org/10.35840/2631-5068/6512.

8. Lambert, M., Mahseredjian, J., Martı'nez-Duró, M., \& Siroi, F. (2015). Magnetic Circuits within Electric Circuits: Critical Review of Existing Methods and New Mutator Implementations. IEEE Transactions on Power Delivery. 30(6), 2427-2434. https://doi.org/10.1109/ TPWRD.2015.2391231.

9. Arushanyan, O., Volchenskova, N., \& Zaletkin, S. (2013). A method for solving the Cauchy problem for ordinary differential equations using Chebyshev's series. Computational methods and programming, 14, 203-214.

10. Katrich, S. A. (2015). Computing features of minimization of the error in the approximation of functions on chebyshev interpolation units. Vectnik Taganrogckogo inctituta imeni A. P. Chehova. Fizikomatematicheckie i ectectvenn'ie nauki, (1), 67-72. ISSN 2225-501X. eISSN: 2306-2037.

11. Tokmakov, I. (2015). Modeling of electromechanical transients in asynchronous motors based on the use of Chebyshev's polynomials. Electrical Engineering and Power Engineering, (2), 35-41. https://doi. org/10.15588/1607-6761-2015-2-5.

12. Trigub, R. (2016). Polynomials with integer coefficients and Chebyshev polynomials. Ukrainian mathematical news, 13(3), 421-448. 13. Khovanskii, A. (2013). Chebyshev's polynomials and their appeals. Matematicheskoye Prosveshcheniye, 17, 93-106. Retrieved from: https://www.math.toronto.edu/askold/2013\%20Mat-Prosv-17\%20 93-106.pdf.

14. Tykhovod, S., \& Patalakh, D. (2019). Calculation of Transients in Electrical Circuits at the Use of Solution Approximation by Chebyshev's Polynomials. IEEE $20^{\text {h }}$ International Conference on Computational Problems of Electrical Engineering (CPEE). ISBN Information: INSPEC Accession Number: 19247158. https://doi.org/10.1109/ CPEE47179.2019.8949129.

15. Patalakh, D. (2019). Modification of numeral calculation of transients in electric circuits on basis of Chebyshev's polynomials. Electrical Engineering and Power Engineering, (4), 11-24. https://doi. org/10.15588/1607-6761-2019-4-2.

16. Boor, C., de Höllig, K., \& Riemenschneider, S. (2013). Box splines. Springer Science \& Business Media. https://doi.org/10.1007/978-14757-2244-4_1.

17. Pankiv, V. I., Tankevich, Ye. M., \& Lutchin, M. M. (2014). Approximation of the characteristics of the magnitisation of current transformers. Works of the Institute of Electrodynamics of the National Academy of Sciences of Ukraine, 37, 82-90.

\section{Удосконалення методів моделювання перехідних процесів у трансформаторах на основі магнітоелектричних схем заміщення}

\section{Д. Г. Паталах, А. М. Приходько, К.А. Лут, С. М. Тиховод}

Національний університет «Запорізька політехніка», м. Запоріжжя, Україна, е-mail: stikhovod@gmail.com

Мета. Застосування вдосконаленого числового методу розрахунку перехідних процесів в електричних колах 
для моделювання електромагнітних процесів у нелінійних магнітоелектричних колах, а також розробка схемної моделі методу, що приводить до зручності розрахунку.

Методика. Апроксимація функцій поліномами Чебишева, числові методи інтегрування диференціальних рівнянь, матричні методи, сплайн-інтерполяція, програмування, теорія електричних і магнітних кіл.

Результати. На основі відомого методу аналізу перехідних процесів у лінійних електричних колах розроблено метод числового розрахунку перехідних процесів у нелінійних магнітоелектричних схемах заміщення трансформаторів. Запропонований метод дозволяє скоротити процесорний час при моделюванні електромагнітних процесів у трансформаторах. Показано приклад застосування розробленого методу. На підставі описаного методу розроблена комп'ютерна програма для моделювання перехідного електромагнітного процесу в однофазному трансформаторі. Даний приклад показав скорочення процесорного часу більш ніж у чотири рази в порівнянні з прикладами розрахунків, виконаними на підставі інших відомих методів.

Наукова новизна. У даній роботі використовується метод, в якому рішення диференціальних рівнянь стану представлено у вигляді розкладання в ряд за ортогональними поліномами Чебишева. У роботі застосована поліноміальна апроксимація не самої функції рішення, а i. похідної, що значно знижує похибку інтегрування диференціальних рівнянь. Диференціальні рівняння стану перетворюються в лінійні алгебраїчні рівняння для спеціальних зображень функцій рішення. Розроблено принцип побудови магнітоелектричних схем замішення, в яких фігурують зображення функцій рішення. Зображення істинних динамічних струмів і магнітних потоків у запропонованій схемі заміщення інтерпретуються як постійні струми й постійні магнітні потоки. Використаний метод показав переваги в точності й часі моделювання перехідних електромагнітних процесів перед іншими відомими методами, заснованими на застосуванні магнітоелектричних схем заміщення.

Практична значимість. Розроблений метод відкриває можливість використання апарату теорії електричних і магнітних кіл для роботи із зображеннями струмів і магнітних потоків. Розроблена комп'ютерна програма для аналізу перехідних процесів в однофазному трансформаторі. На підставі цього розробляється універсальний програмний комплекс для розрахунку перехідних процесів у трансформаторах різних конструкцій.

Ключові слова: перехідний електромагнітний процес, диферениіальні рівняння, схемна модель, поліноміальна апроксимація, поліноми Чебишева, трансформатор

The manuscript was submitted 18.08.20. 